\title{
Engineering Curriculum Readiness: Implementing an Analytical and Communication Skills Building Course for the Technical Disciplines
}

\author{
Barbara Christe, $\mathrm{PhD}$ \\ Engineering Technology Department \\ IUPUI \\ Indianapolis, United States \\ bchrist2@iupui.edu
}

\author{
Alison Stevenson \\ Engineering Technology Department \\ IUPUI \\ Indianapolis, United States \\ aland@iupui.edu
}

\begin{abstract}
Many domestic and international students arrive at college lacking the skills needed for academic careers in engineering or engineering technology. To support academic progress and develop essential skills, TECH 101, Engineering Technology Fundamentals, was proposed, approved, and funded by the School of Engineering and Technology at a large urban public university. The course offered students the preparatory skill development needed to begin an engineering or engineering technology major. TECH 101 facilitated a completely different approach, utilizing a very rare collaboration. Course design and implementation were championed by an experienced engineering technology instructor and a uniquely qualified faculty member whose background includes both transition to college expertise as well as second language acquisition. Drawing the two diverse skill-sets together resulted in context-based activities closely integrated with hands-on technical work, as well as development of a technical vocabulary and English language skills. A small group of learners participated in the initial course offering in the fall of 2014. This Work In Progress paper will explore the unique technical and preparatory course components that promote the support of underprepared domestic and international students.
\end{abstract}

Keywords-retention, remediation, engineering education

\section{INTRODUCTION}

In 2005, a joint report from the National Science Foundation and the National Academy of Engineering [1] framed the priorities for improvement in academic institutions involved in engineering education. The group warned that, in order to meet the demands for engineering graduates, remedial coursework must be available and well-crafted. In addition, the report encouraged educators to incorporate engineering concepts into developmental education. However, the dearth of scholarly research associated with discipline-specific remedial educational experiences in engineering and engineering technology seems to document that few institutions heard this decade-old warning.

At some colleges and universities, especially less-selective institutions, many students arrive on campus lacking the academic and personal skills required for success in engineering or engineering technology programs. The typical support solution for these deficiencies is to require enrollment in developmental mathematics and English courses, guided by placement tests [2]. As a result, the academic pathway toward enrollment in discipline-specific courses may be a long one. Student attrition during the remedial period may be substantial [3].

Vincent Tinto, the student retention theorist, has asserted that student access without support is not opportunity [4]. This perspective may lead educators to conclude that admitted students should receive highly engaging and academically appropriate support services that could promote growth, persistence, and achievement. Utilizing research results [5] associated with persistence factors identified in student populations in engineering technology served by urban public institutions, discipline-specific developmental coursework seemed to be appropriate approach to promote academic success. Important conclusions from the literature shaped the intervention, including personal goals centered around both degree attainment and discipline understanding, academic collaboration (as opposed to social connections), strong faculty relationships, and adaptability surrounding the student's academic role. All of these factors collectively can be generalized by a sense of belonging and a sense of purpose.

Donna Riley, in a March, 2015 Prism article stated, "Fouryear institutions must no longer cherry-pick students able to withstand engineering's 'rigors'.'[6] The prominent National Science Foundation-affiliated author strongly advocated for a "resource-rich" environment that includes substantial academic support. In addition Riley held the provocative position that "there is no situation from which one can 'never' become an engineer." Riley's stance strongly supports the notion of intertwining remedial content embedded in discipline-specific material and activities.

With a desire to support underprepared learners admitted to an urban public university, two faculty members identified and designed the delivery of a discipline-integrated support course to engineering and engineering technology learners, as a supplement to additional developmental mathematics and English coursework. 


\section{Course OBJectives AND DESIGN}

TECH 101 was created to cultivate fundamental analytical and communication skills for students who were unable to meet the pre-requisites for the first technical course in the engineering technology curriculum, TECH 105, Engineering Technology Fundamentals. TECH 105 requires students are ready for freshman composition and pre-college algebra. Many learners were international students or who may have graduated from an underperforming high school. As a result, participants in the first TECH 101 generally lacked a basic knowledge of mathematics or the ability to communicate effectively in English, either written or spoken, or both. In addition, engineering learners could utilize TECH 101 in order to maintain full-time enrollment while enhancing technical skills and progressing toward technical courses required in the curriculum.

While academic skill building was inherent in the course design, objectives related to the exploration of the role of a college student associated with the common practices, codes, values, and interactions associated with the collegiate culture, were integral to the successful delivery of TECH 101. The instructors hoped to cultivate the positive attributes of resilience and adaptability in TECH 101 learners. Factors associated with persistence were tightly woven into the discipline-specific material.

Course objectives were designed to align with the expectations of coursework in TECH 105. In collaboration with the freshman engineering technology instructors, the following course objectives were identified:

After completion of the course, the student should be able to:

- Create graphical representations of data

- Describe and define common metric prefixes

- Demonstrate basic unit conversion applications

- Identify and apply the scientific method to the investigative process

- Communicate the results of a scientific experiment using a generally accepted lab report format

- Create written technical reports using WORD software

- Create fundamental spreadsheets and use them to solve basic problems

- Use spreadsheet software to create graphs and charts

- Develop an effective technical vocabulary

- Describe and apply the concepts of effective teamwork

- Demonstrate an ability to meet deadlines and instructor expectations.

To promote successful completion of the course objectives, several key course components were identified including the use of weekly vocabulary words, a question of the day, a student presentation, written examinations, and laboratory reports.

\section{A. Question of the Day}

The question of the day technique utilized a scientific prompt drawn from the Science Teacher's Activity-a-Day [7] and the Science Question of the Day [8]. This process fostered group collaboration and brainstorming to determine a solution to the prompt. The course instructor guided the investigation by careful evaluation of each word in the question. The questions were often tied to the fundamental concepts associated with the laboratory experience planned for the week. The students' effort in arriving at a solution to the question of the day served as preparation for the vocabulary and scientific theory needed for the weekly topic and hands-on experiences.

\section{B. Vocabulary Words}

Each week, five words were provided to the students, typically associated with the technical concept under examination. For example, during the lesson associated with observations and the scientific method, vocabulary words included observation, bias, appearance, quality, and quantity. Flash cards were utilized to reinforce understanding, with time spent explaining how flash cards should be incorporated into study techniques. The students utilized multiple online dictionaries to evaluate the various entries for the word and assorted meanings, utilizing context to be able to determine the appropriate definition, and choosing the most succinct definition; which allowed them to practice their summarizing skills as well as using contextual clues to define new words.

Vocabulary words served as models to explore the concepts of context, homophones, and online translator tools. Learners were guided through the examination of dictionary entries to identify the particular meaning most likely to be associated with TECH 101 content. An example of this process was undertaken for the term "mass," utilized in the density content area, a challenging term for some international students. An online dictionary was consulted and the various meanings explored. The definition as a Christian service was discussed as well as the dictionary labels such as "related to medicine." Students were guided to evaluate and select the appropriate meaning.

\section{Reflective Discussion}

Throughout the course, open discussion between both instructor and learners as well as among students was highly encouraged. In the beginning of the course, it was explicitly explained that this was a safe space for questions and for practicing English. A supportive environment among peers was encouraged and fostered, which lead to students being very open to class discussions and supporting each other when questions arose. Diminishing the power distance between students and professor was a vital step in promoting role understanding, behavioral expectations, and overall course success.

Discussions were always conducted with the instructor seated with the students facilitating, but not leading, the communication. Often, the students would rely heavily on the instructor to answer questions, expecting immediate answers instead of working out a solution individually or collectively. Once this was noted, the instructor would set up a hands-on 
activity, facilitate the necessary discussion, and then excuse herself for a period of time. The students were left to work together and solve problems without the intervention of the instructor. This proved very successful. The students became excellent problem solvers on their own, and became proud of their work and new-found abilities.

\section{Laboratory Reports}

Formal and written laboratory reports developed skills associated with summarizing, communicating technical terms in English, and conveying data. The requirement demanded significant attention to detail, comprehension of faculty expectations, and ability to meet deadlines. Throughout the semester, assignments increased in depth and complexity, building on previous understandings.

The instructor was surprised at the significant deficit in computer literacy. Course laboratory reports offered students task-specific activities to promote fundamental skill building including keyboarding, work processing commands and techniques, access to online data storage, and functions within course management software. Careful emphasis to cultivate computer literacy was an essential course outcome in order to promote success in future courses.

\section{HANDS-ON ACTIVITIES}

Hands on activities were crucial. Experiences were drawn from a variety of resources including The Sourcebook for Teaching Science [9], resources at the Discover Engineering website [10], and Engineering World Health [11]. Some of the experiential learning projects are described in this section.

\section{A. Density of a Tootsie Roll}

In the pre-work for this experience, the vocabulary words of the day explored the terms in the density equation. The question of the day dealt with how and why density should be calculated and the students practiced using and understanding the formula. As part of the lab, the students used the formula $\mathrm{D}=\mathrm{M} / \mathrm{V}$ to calculate the density of different sized Tootsie Rolls. They made a hypothesis about whether the size would affect the density and then used scientific language to explain their results. The students also used very simple unit conversions with the scales. Learners were introduced to tools to help convert and understand the difference between English and Metric Units, as the international students were unfamiliar with English Units.

\section{B. Paper Airplane}

This experience was completed at the beginning of the semester and primarily focused on clear communication skills and attention to detail, but was integrated with engineering design. Students were tasked with designing a paper airplane that would fly the farthest of any in the class. They were then asked to write instructions for the instructor to create a paper airplane exactly like the one they created. A competition took place to see whose plan flew the farthest and then to see if the instructor's version was identical to the original. A final discussion after the laboratory helped the students understand the need for clear word choices. In addition, learners postulated how their instructions could have been improved. The need for engineers to possess excellent written communication skills was also discussed.

The written instructions and a summary of the findings were the written deliverables for this activity.

\section{Tower Project}

This lab engaged students in engineering design, formal written communication skills, and a basic understand of the potential social impacts associated with the discipline of engineering. The discussion for this lab was comprised of research the construction of towers around the world and the race to build the tallest building. A visit to the website for the Burj Khalifa building [12] sparked interesting discussion, as the international students were very familiar with this building in Dubai.

Once students were familiarized with the positive and negative social impact of engineering design, specifically the design of the tallest building in the world, they began their own design of 'towers'. The students were each given a box of toothpicks and unlimited mini marshmallows. They were tasked with building the tallest tower, the minimum height had to be 12 inches, and it had to withstand a breeze of a fan. They concluded this experience with a written report.

\section{Robot Arm}

Students were given a box of various office supplies and were tasked with building a robot arm that would pick up a cup holding paper clips and empty this cup into another cup roughly one foot away. This experience included little discussion and preparation as a way to help the students hone their design and teamwork skills. The vocabulary words for the week were centered around team work.

Students were given the basic instructions for this lab and were left alone for approximately 15 minutes to begin their design process. After that time, they were shown a short video of students who had previously completed this project and were allowed more time to work on their design. Learners met the objective and concluded the class with a discussion about their work together and how teamwork might be challenging in a professional engineering environment. Students completed a written laboratory report as homework.

\section{E. Estimating}

Somewhat surprisingly, this experience was noted as a favorite by the class members. The objective of this lab was to explore the importance of estimating within the engineering discipline, and to practice using basic tools of measurement. Discussions began with brainstorming how and why engineers should have well-honed estimating skills. The lab work required a variety of estimating skills, including estimating weight, length, height, and number of objects. Students completed a worksheet where they estimated several objects such as number of objects in a jar, the temperature of the classroom, the width of the classroom, the height of their instructor, etc. Next learners took actual measurements of these items. Finally, students wrote a reflection describing 
what they learned as well as why estimating skills are important for engineers. The following class, the instructor offered some suggestions on how to best complete the estimates required for the activity.

\section{OBSERVATIONS}

The students in Tech 101 were all studying different engineering technology disciplines, which created a wonderfully diverse environment for discussions and teamwork. Students were extremely conscientious and engaged in the learning process, which resulted in fruitful discussions and thoughtful responses in their written lab reports and reflections.

The greatest challenge for learners in this course was the successful completion of the written report. The first lab report of the semester was completed step-by-step as a class; with each student submitting his individual report. Each week, students were tasked with completing more of their lab report on their own.

The students experienced difficulty when asked, at the end of the semester, to name all parts of the lab report. Upon reflection, this course should have included an entire class period devoted to the written report, the importance of understanding its different sections, and how to produce a quality product. Because this is an important fundamental skill for engineering students, special consideration should be given to this skill in a remedial setting.

The course activities promoted a deeper understanding of the role of a college student (in the United States), especially the responsibilities, expectations, and the keys to success in the engineering and engineering technology disciplines.

Four students began the course, one student withdrew from the university. Of the three remaining students, all are still enrolled in their majors and successfully completing $\mathrm{TECH}$ 105.

\section{CONCLUSIONS}

Upon completion of TECH 101, students were asked their opinions and concerns both in a formal, anonymous course evaluation and as part of a class discussion. All students in the class agreed that they found the course beneficial and taught at a speed compatible with their learning, even if they had been hesitant to enroll initially. Throughout the course, the improvement in confidence of the students was noticeable, as was the production and success in course assignments.

A familiarity with the jargon and tools used in an engineering classroom supports and encourages the underprepared student, especially those who are studying in a foreign language. This course provides those skills in a nurturing setting where students can test their new-found skills in authentic, discipline-specific environments, which is a best practice for second language development.

In future semesters, the instructors will fine-tune the course content, with special emphasis to maintain relevancy to the current student population. The Tech 101 pilot demonstrates that discipline-specific developmental coursework fosters both technical fluency as well as college-student role understandings in a highly satisfactory way. Learners enjoyed the hands-on activities and responded to the escalating instructor expectations. Initial findings suggest that TECH 101 supports student success once learners begin engineering or engineering technology curricular coursework.

\section{ACKNOWLEDGMENT}

The authors appreciate the administration of the School of Engineering and Technology as well as University College at IUPUI for their willingness to support innovative approaches to engage underprepared learners.

\section{REFERENCES}

[1] Pekow, C. "Science Committee questions pathways to engineering education." Diverse Issues in Higher Education (2005) 22 pp. 6-7.

[2] Hurtado, I., Knight, C., Peralta, R., \& Crichigno, J. "A highly successful summer accelerator math program in a Hispanic serving institution" ASEE Annual Conference, Atlanta, GA. (2013)

[3] Ohland, M., Sheppard, S., Lichtenstein, G., Eris, O., Chachra, D., \& Layton, R. "Persitence, engagement, and migration in engineering programs." Journal fo Engineering Education, (2008) 97, pp. 259-278.

[4] Tinto, V. "Leaving college: Rethinking the causes and cures of student attrition" ( $2^{\text {nd }}$ ed.) Chicago, IL: University of Chicago. (1993).

[5] Christe, B. "Persistence factors associated with first-year engineering technology learners." Journal of College Student Retention: Research, Theory \& Practice, (2015), 17(2).

[6] Riley, D. “A way up for low-income students" ASEE Prism, (2015), 24(7), pp. 44.

[7] Walke, P, Wood, E. "The Science Teacher's Activity-A-Day." San Francisco: Jossey-Bass. (2010).

[8] Finton, N.. "Science Question of the Day." New York: Scholastic. (2007)

[9] Herr, N. "The Sourcebook For Teaching Science." San Francisco: Jossey-Bass. (2008).

[10] http://www.discovere.org/our-activities

[11] http://www.ewh.org/students/2013-12-06-15-44-37/advanced-kits/ewhkits-ohrm

[12] http://www.burjkhalifa.ae/en/ 